\title{
PADRÃO DE ESPECIALIZAÇÃO DO COMÉRCIO INTERNACIONAL AGRÍCOLA BRASILEIRO: UMA ANÁLISE POR MEIO DE INDICADORES DE COMPETITIVIDADE
}

\author{
Mygre Lopes da Silva* \\ Alison Geovani Schwingel Franck** \\ Rodrigo Abbade da Silva*** \\ Daniel Arruda Coronel ${ }^{* * * * *}$
}

RESUMO: Este trabalho buscou analisar o padrão de especialização do comércio internacional do setor agrícola brasileiro, identificando os setores produtivos mais dinâmicos, no período entre 1999 e 2014. Para isso, calcularam-se os indicadores de Taxa de Cobertura das Importações (TC), de Comércio Intraindústria (CII) e de Concentração Setorial das Exportações (ICS). Os dados foram coletados no Sistema de Análise de Informações do Comércio Exterior (Alice Web). Os resultados indicaram que, apesar de o país apresentar pauta exportadora agrícola relativamente diversificada, esta continua a ser competitiva predominantemente nos setores de suco de laranja, açúcar e frango. A partir disso, é possível inferir que os setores especializados no comércio internacional são aqueles que apresentam vantagens comparativas convencionais.

PALAVRAS-CHAVE: Exportações; Brasil; Setor agrícola.

\section{SPECIALIZATION PATTERN OF BRAZILIAN AGRICULTURAL INTERNATIONAL COMMERCE: ANALYSIS BY INDEXES OF COMPETITIVENESS}

\begin{abstract}
The specialization pattern of Brazilian agricultural international commerce is investigated by identifying the more dynamics production sectors between 1999 and 2014. Indexes of Import Cover rates (TC), Intra-Industrial Commerce rates (CII) and Sectorial Concentration of Imports (ICS) are evaluated.

\footnotetext{
Docente Adjunta da Fundação Universidade Federal do Pampa (UNIPAMPA), Brasil.

** Mestrando em Administração pela Universidade Federal de Santa Maria (UFSM), Brasil.

*** Doutorando em Administração pela Universidade Federal de Santa Catarina (UFSC), Brasil.

**** Docente Adjunto do Departamento de Economia e Relações Internacionais, com atuação permanente nos Programas de Pós-Graduação (Stricto sensu) em Gestão de Organizações Públicas, de Agronegócios e de Economia e Desenvolvimento, da Universidade Federal de Santa Maria (UFSM) e Bolsista de Produtividade do CNPq. E-mail: daniel.coronel@uol.com.br
} 
Data were collected within the system for Information Analysis of External Commerce (Alice Web). Although Brazil has a diversified agricultural export program, results show that the country has predominantly competitiveness in orange juice, sugar and broilers. One may infer that specialized sectors in international commerce represent comparative conventional advantages.

KEY WORDS: Exports. Brazil. Agricultural Sector.

\section{INTRODUÇÃO}

A agricultura possui conhecida importância desde o início da vida humana, e, como um fenômeno relacionado a esta, não pode ser vista apenas como fator mitigador da fome, estando relacionada a outros aspectos, como o da atividade lucrativa e o desenvolvimento das populações, e, mais tardiamente, como componente da gestão responsável dos recursos do planeta e controle das consequências ambientais.

Segundo o Ministério da Agricultura, Pecuária e Abastecimento (MAPA, 2015), o Brasil é um dos líderes mundiais na produção e exportação de vários produtos agropecuários em termos de volume. Ainda segundo o MAPA, o Brasil tem potencial para se tornar líder na produção de biocombustíveis, produzidos a partir de cana-de-açúcar e óleos vegetais, além de outros produtos como algodão, milho, arroz, frutas frescas, cacau, castanhas, nozes, suínos e pescados. Porter (1993), em suas investigações e análises sobre as vantagens competitivas das nações, reitera que, para que uma nação se consolide e se mantenha no mercado, é necessário que ela tenha vantagens competitivas em relação às demais nações, como produtos diferenciados e diversidades tecnológicas, e tal nação deve manter sua eficácia na vantagem competitiva.

Assim, para a economia brasileira, a vantagem competitiva deve-se, principalmente, aos fatores edafoclimáticos favoráveis à produção, tais como abundância de chuvas e de sol, além de uma temperatura alta estável ao longo do ano; à tecnologia desenvolvida pelos centros de pesquisas; à grande abundância de terras para o cultivo; à boa qualidade dos solos; à topografia plana, entre outros (WAQUIL et al., 2004).

Segundo Conceição e Conceição (2014), a participação das exportações 
do setor agrícola brasileiro na balança comercial tem sido crescente e superior ao desempenho dos demais setores que compõem a balança comercial, desde o início do processo de abertura, em 1990. Ainda segundo tais autores, entre os fatores que explicam o desempenho positivo do setor agrícola, destaca-se a queda nos estoques de grãos, que vem ocorrendo desde o final da década de 1990, e maior demanda de países em desenvolvimento. Mudanças nos destinos de parte significativa das exportações brasileiras de produtos agropecuários têm exigido adaptações e melhorias no processo de comercialização dos produtos.

Nas últimas décadas, importantes transformações vêm ocorrendo no ambiente produtivo nacional e internacional, e os mercados mais competitivos vêm obrigando as empresas a se adequarem a um padrão mais rigoroso de eficiência econômica (CARVALHO; BIALOSKORSKI NETO, 2011). Desta forma, a utilização de dados e análise de informações é fundamental para subsidiar a formulação de políticas corretas e adequadas para o setor rural (INSTITUTO BRASILEIRO DE ECONOMIA, 2017). Portanto, faz-se necessário verificar o desempenho do setor agrícola brasileiro para identificar os setores mais competitivos no intuito de fomentar o desenvolvimento de políticas voltadas ao crescimento e ao desenvolvimento do setor.

Neste sentido, este trabalho tem como objetivo geral analisar o padrão de especialização do setor agrícola brasileiro, no período 1999 a 2014, cujo marco inicial representa o ano em que o Brasil adota o regime de câmbio flutuante (VIANNA; BRUNO; MODENESI, 2010). Especificamente, pretende-se analisar os setores produtivos mais dinâmicos do setor, bem como compreender a composição de sua pauta exportadora.

Além desta introdução, o artigo está organizado da seguinte forma: a seção 2 apresenta o referencial teórico; na sequência, a seção 3 apresenta a estrutura da pauta exportadora do setor agrícola; na seção 4 é apresentada a metodologia; na seção 5, os resultados são analisados e discutidos; e, por fim, é apresentada a conclusão. 


\section{REFERENCIAL TEÓRICO}

O comércio intraindústria é o intercâmbio comercial de produtos de um mesmo segmento industrial entre dois países ou grupos de países. Em contrapartida, no comércio interindústria, as trocas ocorrem entre diferentes produtos de um mesmo segmento de atividade. Grubel e Lloyd (1975) lançaram os pilares para o cálculo do comércio intraindústria; ao considerarem a importância do comércio intraindústria, definiram o que seria mais tarde denominado de "índice Grubel-Lloyd", que permitia calcular qual o tipo de troca comercial (se inter ou intraindustrial) que um país possuía em relação ao comércio mundial, ou em relação a um subconjunto de parceiros comerciais, bem como permitia o cálculo para o total do comércio de mercadorias ou para um subconjunto de indústrias.

Para Bergstrand e Egger (2006), a investigação empírica a respeito dos fluxos comerciais lançou a observação fundamental de que a maior parte do comércio internacional - propriamente entre os países industrializados - era intraindustrial e não interindustrial. Tal observação foi singular para os economistas do comércio internacional, visto que suas teorias seguiam as predominantes do comércio internacional na época - as teorias ricardiana e Heckscher-Ohlin - e elas só explicavam uma parte do comércio internacional. Esses fatos motivaram vários teóricos do comércio a combinar a organização industrial e as literaturas do comércio internacional para oferecer teorias formais e com mais acuidade sobre o comércio intraindustrial.

De acordo com Soo (2016), em sua obra, Helpman e Krugman (1985) combinam aspectos de várias teorias do comércio internacional, fornecendo imagem mais unificada das razões do comércio internacional. De acordo com o autor, Helpman e Krugman (1985) combinam a dotação de fatores de HeckscherOhlin com a concorrência imperfeita de Dixit-Stiglitz-Spence para mostrar o padrão de comércio que emerge quando as teorias tradicionais e as novas teorias comerciais são combinadas.

Desta forma, de acordo com Dion (2004), a teoria de Helpman e Krugman elucida que o comércio entre países semelhantes pode ser explicado caso se permita que economias de escala específicas para cada país, possam promover 
a especialização (mesmo se os países tiverem dotações idênticas de fatores). Por economias de escala se entende quando ocorre o aumento da produção de um bem acompanhado de uma redução nos seus custos. Essa redução pode ocorrer por utilização de métodos produtivos mais automatizados ou mais avançados, ou também pode estar relacionada às etapas de produção e comercialização (POSSAS, 1993).

Quanto à análise do setor agrícola, pelo viés do comércio intraindústria, em caráter global, merece destaque o artigo de Jambor e Leitão (2016), que trouxeram como fator inovador a investigação dos determinantes específicos do comércio intraindústria vertical do setor agroalimentar entre os novos Estados-Membros da União Europeia e os outros países da UE para o período de 1999-2010, por meio da aplicação de um modelo de dados de painel dinâmico.

Especificamente para o Brasil, de acordo com Carmo (2010), as averiguações empíricas acerca do comércio intraindustrial tiveram os seus primeiros desdobramentos em meados da década de 1980, e desde então vêm recebendo grande atenção por parte dos pesquisadores. Quanto à importância dessas averiguações, Carmo (2010) ressalta que elas se tornaram mais importantes principalmente pelas transformações estruturais ocorridas na economia brasileira durante os anos 90, tais como a abertura comercial, a formação do Mercosul, a assinatura de diversos acordos bilaterais de comércio, a entrada de empresas transnacionais etc.

Neste sentido é que a análise desenvolvida neste trabalho se diferencia dos trabalhos anteriores, pois, ao trabalhar com o fluxo de comércio brasileiro com o mundo, procurou-se não só verificar a evolução do índice de comércio intraindústria para o fluxo de comércio internacional, mas, principalmente, identificar o padrão comercial do setor agrícola brasileiro de 1999 a 2014.

\section{A ESTRUTURA DAS EXPORTAÇÕES BRASILEIRAS DO SETOR AGRÍCOLA}

De 1999 a 2014, as exportações agrícolas totais cresceram 417,45\%, já as do Brasil apresentaram um crescimento de $367,3 \%$. Por sua vez, as importações do setor cresceram 181,17\%, e as totais do país cresceram 364,6\%. As exportações 
agrícolas cresceram mais em relação ao total exportado pelo país, e as importações, por sua vez, cresceram menos.

Segundo Carvalho (2006), grande parte do desenvolvimento do setor agrícola brasileiro ocorreu pela liberalização econômica, principalmente durante a década de 1990. Sobretudo no caso das sociedades latino-americanas, como a brasileira, a falência do modelo nacional-desenvolvimentista calcado no processo de industrialização via substituição de importações e a necessidade da globalização econômica com incremento da capacidade de redirecionar as políticas domésticas, fizeram com que houvesse entusiasmo pelo desempenho do setor agrícola.

De acordo com a Figura 1, pode-se observar que o Brasil exporta mais produtos agrícolas do que importa. Para Brandão, Rezende e Marques (2005), o crescimento da exportação agrícola é fruto de maior produção, já que o país vem aumentando sua produtividade graças à evolução tecnológica, o que vem beneficiando vastas áreas para a prática.

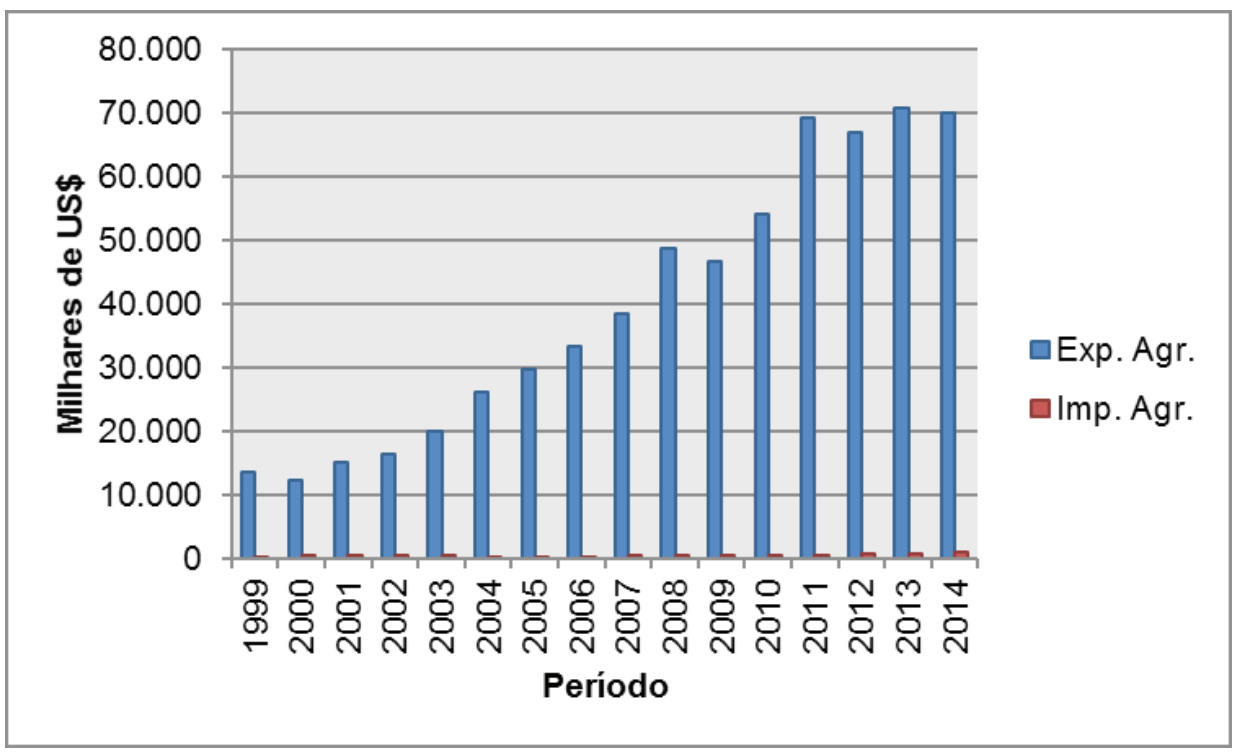

Figura 1. Exportações $(\mathrm{X})$ e Importações (M) agrícolas brasileiras (em milhões US\$ FOB) Fonte: Elaboração própria a partir dos dados do Sistema Alice Web.

Ainda referente à Figura 1, segundo o MAPA (2015), pode-se considerar que o Brasil é um dos maiores produtores e exportadores mundiais de alimentos e 
fibras graças à crescente participação do País no mercado internacional, resultado da combinação de fatores como clima propício, investimento em tecnologia, extensão territorial cultivável e qualidade dos produtos. O Brasil exporta para mais de 180 países, tendo como principais mercados a China, a União Europeia e os Estados Unidos, além dos países do Mercosul.

A Organização das Nações Unidas para Agricultura e Alimentação (FAO, 2015) e a Organização para a Cooperação e Desenvolvimento da Europa (OCDE, 2015) consideram que o Brasil assumirá a liderança das exportações mundiais do setor agrícola em 2024, consolidando, assim, os avanços que o setor registrou no país nos últimos anos.

De acordo com a Tabela 1, os produtos que obtiveram maior crescimento percentual na pauta exportadora brasileira entre os anos de 1999 e 2014 foram os de carne suína $(1062,1 \%)$, carne bovina (776,2\%), soja e derivados (727\%) e frango (725,3\%). Com isto, além do complexo soja, é notório o crescimento do comércio de carnes na pauta exportadora brasileira.

Tabela 1. Estrutura das exportações agrícolas brasileiras segundo grupos de produtos em (\% relativo valor Free On Board - FOB)

(Continua)

\begin{tabular}{|c|c|c|c|c|c|c|c|c|c|c|c|c|c|c|c|c|c|}
\hline $\begin{array}{l}\text { Produtos/ } \\
\text { períodos }\end{array}$ & ळ & §્ণ & ఠ్రి & ڤิ & $\stackrel{\overbrace{}}{ి}$ & ષ્ণ & ڤ્ڤ & ๕્ণ & ڤ్తి & 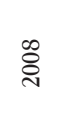 & હેे & 옥 & $\overrightarrow{\bar{乛}}$ & 고ํ & $\stackrel{n}{\stackrel{\sim}{1}}$ & $\stackrel{\varpi}{\stackrel{\sim}{*}}$ & $\begin{array}{c}\text { Taxa } \\
\text { de cresc } \\
1999 \text { a } \\
2014\end{array}$ \\
\hline $\begin{array}{l}\text { Soja e } \\
\text { derivados }\end{array}$ & 28,1 & 34,2 & 35,5 & 37,0 & 40,6 & 38,6 & 31,8 & 28,0 & 29,7 & 37,1 & 37,1 & 31,6 & 35,0 & 39,1 & 43,8 & 44,9 & 727,0 \\
\hline $\begin{array}{l}\text { uco de } \\
\text { ranja }\end{array}$ & 9,2 & 8,4 & 5,6 & 6,4 & 5,9 & 4,1 & 3,7 & 4,4 & 5,9 & 4,1 & 3,5 & 3,3 & 3,4 & 3,4 & 3,2 & 2,8 & 58,7 \\
\hline Fumo & 6,7 & 6,8 & 6,3 & 6,1 & 5,4 & 5,4 & 5,7 & 5,2 & 5,8 & 5,6 & 6,5 & 5,1 & 4,2 & 4,9 & 4,6 & 3,6 & 173,7 \\
\hline Frango & 6,6 & 6,7 & 8,9 & 8,5 & 9,0 & 9,9 & 11,8 & 9,6 & 12,0 & 13,1 & 11,4 & 11,5 & 11,0 & 10,8 & 10,5 & 10,5 & 725,3 \\
\hline $\begin{array}{l}\text { Carne } \\
\text { bovina }\end{array}$ & 5,8 & 6,4 & 6,8 & 6,8 & 7,7 & 9,5 & 10,1 & 11,7 & 11,3 & 10,5 & 8,3 & 8,4 & 7,3 & 8,1 & 9,0 & 9,8 & 776,2 \\
\hline Carne suína & 0,9 & 1,4 & 2,4 & 2,9 & 2,7 & 2,9 & 3,8 & 3,0 & 3,1 & 2,9 & 2,5 & 2,3 & 1,9 & 2,1 & 1,8 & 2,1 & 1062,1 \\
\hline Açúcar & 14,1 & 9,7 & 15,2 & 12,8 & 10,7 & 10,1 & 13,1 & 18,5 & 13,3 & 11,3 & 18,0 & 23,6 & 21,6 & 19,2 & 16,7 & 13,5 & 395,1 \\
\hline Café & 18,2 & 14,5 & 9,4 & 8,5 & 7,7 & 7,9 & 9,8 & 10,1 & 10,1 & 9,8 & 9,2 & 10,6 & 12,6 & 9,7 & 7,5 & 9,5 & 170,4 \\
\hline
\end{tabular}


(Conclusão)

\begin{tabular}{|c|c|c|c|c|c|c|c|c|c|c|c|c|c|c|c|c|c|}
\hline $\begin{array}{l}\text { Produtos/ } \\
\text { períodos }\end{array}$ & $\stackrel{\partial}{\sigma}$ & ఫ్రి & ర్స & ઠิ & 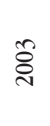 & 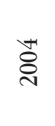 & ڤ్ & ఫ્స & ڤ్సి & \&్సે & ठ્సે & $\stackrel{\circ}{\stackrel{\sim}{\sim}}$ & $\overrightarrow{\vec{N}}$ & 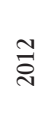 & $\stackrel{\sim}{\stackrel{\sim}{*}}$ & $\stackrel{\vec{\sim}}{\vec{\sim}}$ & $\begin{array}{c}\text { Taxa } \\
\text { de cresc. } \\
1999 \text { a } \\
2014\end{array}$ \\
\hline adeira & 0,3 & 2,0 & 9,9 & 10,8 & 10,4 & 11,7 & 10,2 & 9,5 & 8,7 & 5,7 & 3,6 & 3,5 & 2,8 & 2,8 & 2,8 & 3,2 & 61,3 \\
\hline
\end{tabular}

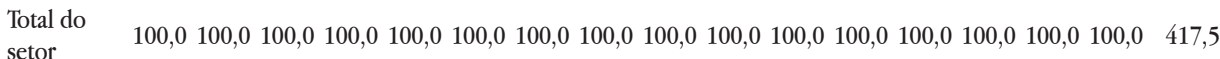

Fonte: Elaboração própria a partir dos dados do Sistema Alice Web.

Segundo Veríssimo (2007), boa parte do sucesso de exportação de carnes é pela parceria entre promotores de serviços brasileiros no exterior e os frigoríficos exportadores, o que atrai investimentos estrangeiros e é fundamental para a manutenção e conquista de novos mercados para a carne brasileira. O programa setorial de promoção de exportações da carne brasileira tem tido grande sucesso, apresentando e reconhecendo a carne brasileira como um produto de qualidade superior e altamente disponível. As exportações de carnes brasileiras foram consolidadas, ainda, a partir de uma oferta firme e abundante de matéria-prima, com qualidade, em grande parte, superior à ofertada pelo comércio mundial.

Com relação a isto, o MAPA (2015) afirma que até 2020 a expectativa é de que a produção nacional de carnes suprirá 44,5\% do mercado mundial. Já a carne de frango terá $48,1 \%$ das exportações mundiais, e a participação da carne suína será de $14,2 \%$. Essas estimativas indicam que o Brasil pode manter posição de primeiro exportador mundial de carnes bovina e de frango.

No caso específico da carne bovina e de frango brasileiras, segundo dados do Departamento de Agricultura dos EUA (USDA, 2011), ambas passaram a liderar o mercado mundial após 2003 e 2004, respectivamente. Lima, Moretto e Rodrigues (2011) explicam que o Brasil vem ocupando maior espaço no cenário internacional também em razão de aspectos sanitários, como o surgimento de focos de Encefalopatia Espongiforme Bovina (EEB ou, em inglês, BSE, popularmente conhecida como o "mal-da-vaca-louca") e, mais recentemente, de Influenza Aviária (popularmente conhecida como a "gripe-do-frango"), que resultaram na abertura de novos mercados para os produtos brasileiros.

Já quanto à participação importante da soja, segundo Gasques et al. (2004), o aumento da exportação do complexo soja, assim como ocorreu no comércio de carnes (bovina, suína e de frango), é reflexo da desvalorização da taxa de câmbio, 
a partir de 1999, mantendo a tendência ao longo dos anos segundo a qual o complexo soja adquiriu maior destaque em relação aos demais complexos. Com a desvalorização cambial e consequente aumento do preço da moeda estrangeira e ainda com a diminuição do preço da moeda nacional, os importadores do Brasil puderam adquirir mais reais de produtos exportados pelo valor da moeda nacional destes.

Com a necessidade de uma produção em maior escala, o comércio internacional exigiu do complexo a melhoria na infraestrutura, armazenagem, transporte e distribuição. Neste contexto, a adoção da Lei Kandir impulsionou as exportações de soja em grão, a qual desonerou as exportações de produtos in natura do Imposto sobre Circulação de Mercadorias (ICMS), embora, por outro lado, tenha desestimulando a venda de produtos que poderiam ter maior valor agregado, como farelo e óleo (CORONEL; MACHADO; CARVALHO, 2009).

\section{MATERIAL E MÉTODOS}

Nesta seção, são apresentados os três indicadores utilizados no presente estudo, os quais são frequentemente empregados na literatura para identificar o padrão de comércio internacional de um país e/ou bloco (VASCONCELOS, 2000; ALBUQUERQUE; FERNANDES, 1999; FEISTEL; HIDALGO, 2011).

Estes indicadores permitem verificar o padrão de comércio internacional agrícola brasileiro, no que tange ao fluxo exportador. Assim, analisam-se os produtos mais competitivos, por meio da taxa de cobertura, o tipo de relação de comércio para com os demais países, se intraindustrial ou interindustrial, e a identificação da diversificação ou concentração destes setores na pauta exportadora brasileira.

Desta forma, os três indicadores possibilitam-se uma visão integrada do padrão de comércio exterior agrícola brasileiro, com maior acuidade, o que permite a elaboração de políticas públicas com o intuito de fomentar a sua competitividade.

O primeiro indicador possibilita identificar os setores brasileiros que apresentam vantagem comparativa na produção (mais competitivos). A taxa de cobertura das importações (TC) indica quantas vezes o volume das exportações 
do setor i está cobrindo seu volume de importação. O índice é obtido através da Equação 1:

$$
\boldsymbol{C}_{i j}=\frac{X_{j} / M_{j}}{X_{i} / M_{i}}
$$

em que:

Xij representa as exportações do setor i do país $j$ (BRA);

$M_{i j}$ representa as importações do setor i do país $j$ (BRA);

$\mathrm{X}_{\mathrm{i}}$ representa as exportaçóes totais do país $\mathrm{j}(\mathrm{BRA})$;

$\mathrm{M}_{\mathrm{i}}$ representa as importações totais do país $\mathrm{j}$ (BRA).

Segundo Fontenele, Melo e Rosa (2000), quando $\mathrm{TC}_{\mathrm{ij}}$ é superior à unidade $\left(\mathrm{TC}_{\mathrm{ij}}>1\right)$, identifica-se uma vantagem comparativa em termos de cobertura das exportações, ou seja, as exportações do setor i do país teriam dimensão maior se comparadas às importações do mesmo setor.

O segundo indicador possibilita a caracterização na forma como a vantagem competitiva (inter ou intraindústria) ocorre. O Índice de Comércio Intraindústria (CII), o qual visa caracterizar o comércio do Brasil, consiste na utilização da exportação e importação simultânea de produtos do mesmo setor. Com o avanço e a difusão dos processos tecnológicos entre os países, muda-se a configuração do comércio internacional e o peso das vantagens comparativas (abundância de recursos). Apresenta-se como destaque o crescimento do comércio interindustrial. Conforme Appleyard, Field Jr. e Cobb (2010), diferente do comércio interindustrial, o comércio intraindústria é explicado pelas economias de escala e pela diferenciação do produto.

O indicador setorial do comércio intraindustrial (CII) foi desenvolvido por Grubel e Lloyd (1975) e pode ser apresentado conforme a Equação 2:

$$
\underset{\text { em que: }}{C I I=1} \frac{\sum_{i}\left|X_{i}-M_{i}\right|}{\sum_{i}\left(X_{i}+M_{i}\right)}
$$

$\mathrm{X}_{\mathrm{i}}$ representa as exportações do produto i;

$\mathrm{M}_{\mathrm{i}}$ representa as importações do produto $\mathrm{i}$. 
Quando o indicador CII se aproximar de zero, pode-se concluir que há comércio interindustrial, e, neste caso, o comércio é explicado pelas vantagens comparativas, ou seja, observa-se a presença de comércio entre produtos de diferentes setores do Brasil com os países parceiros. Esse evento pode ser observado ao constatar ocorrência de apenas importação ou apenas exportação do setor i (ou produto i). Por outro lado, quando CII for maior que 0,5 (CII $>0,5)$, o comércio é caracterizado como intraindustrial.

Assim, o padrão de comércio intraindustrial reflete uma pauta exportadora que, por sua vez, sucede uma estrutura produtiva dinamizada em progresso tecnológico e em economias de escala (ampliação de mercados). Todavia, a configuração interindustrial reflete o ordenamento entre os setores produtivos, baseado no uso da dotação de fatores e sob concorrência perfeita.

Esse arranjo explicativo das trocas comerciais pode indicar se determinado participante do comércio internacional alcançou ganhos de competitividade. Ressalta-se que, em meio à profusão de conceitos que foram dados a esse termo, entende-se, neste artigo, diante dos alcances e das limitações dos índices utilizados, que alcançar competitividade internacional significa atingir os maiores níveis de vantagem comparativa revelada e o padrão de inserção intraindustrial.

O terceiro indicador permite discernir sobre concentração ou participação do setor na economia brasileira ${ }^{5}$. O índice de Concentração Setorial das Exportações (ICS), também conhecido como coeficiente Gini-Hirchman, o qual quantifica a concentração das exportações de cada setor exportador i realizadas pelo país $\mathfrak{j}$ (Brasil). O ICS é representado através da Equação 3:

$$
\begin{gathered}
I C S_{i j}=\sqrt{\sum_{i}\left(\frac{X_{j}}{X_{j}}\right)^{2}} \\
\text { em que: }
\end{gathered}
$$

$\mathrm{X}_{\mathrm{ij}}$ representa as exportações do setor i pelo país $\mathrm{j}$ (BRA); e, $\mathrm{X}_{\mathrm{j}}$ representa as exportações totais do país $\mathrm{j}$ (BRA).

\footnotetext{
5 Uma economia com grande parte da produção concentrada em poucos setores pode ser prejudicada pela sua alta dependência nas alterações nos níveis de preços e na demanda internacional de seus produtos e da doença holandesa (BRESSER-PEREIRA; VIANA; CUNHA, 2016).
} 
O ICS varia entre 0 e 1 , e, quanto mais próximo a 1 , mais concentradas serão as exportações em poucos setores e, por outro lado, quanto mais próximo de 0 , mais diversificada será a composição da pauta de exportações (CASAGRANDE; ILHA; FÜHR, 2013).

Os dados relativos às importações e exportações desagregadas por setores seguem o padrão da literatura empírica da área, conforme apresentados por Waquil et al. (2004), acrescido dos setores de carne suína e de madeira. Os códigos utilizados para cada categoria de produto, conforme a Nomenclatura Comum do Mercosul' 2 , são descritos de acordo com a Tabela 2 .

Tabela 2. Classificação do setor agrícola e os códigos da NCM empregados

\begin{tabular}{c|c}
\hline Produtos & Códigos \\
\hline Soja e derivados & $1201 ; 12081 ; 1507 ; 2304 ; 3504002$ \\
Suco de laranja & 20091 \\
Fumo & $2401 ; 2403$ \\
Frango & $02071 ; 160232$ \\
Carne bovina & $0201 ; 0202 ; 02061 ; 02062 ; 02102 ; 16025$ \\
Carne suína & $0203 ; 16024 ; 02063 ; 02101$ \\
Açúcar & 1701 \\
Café & $0901 ; 21011$ \\
Madeira & $44 ; 45 ; 46$ \\
\hline
\end{tabular}

Fonte: Elaborada pelos autores.

Para alcançar o objetivo de explanar o padrão comercial do Brasil, no período 1999-2014, e apresentar os produtos agrícolas em que o país possui maior especialização e competitividade, serão utilizados indicadores baseados nos fluxos comerciais, conforme descritos anteriormente. O banco de dados para o cálculo destes indicadores foi obtido junto à Secretaria do Comércio Exterior (SECEX) do Ministério do Desenvolvimento, Indústria e Comércio do Brasil (MDIC), disponível

$6 \quad$ Para classificar as mercadorias, em 1996, o Brasil passou a utilizar a Nomenclatura Comum do Mercosul (NCM), a qual é utilizada pelos outros integrantes do bloco, baseado no Sistema Harmonizado de Designação e Codificação de Mercadorias (Capítulos SH) - (MDIC, 2015). 
por meio do Sistema de Análise de Informações do Comércio Exterior (Alice Web).

Desta forma, mediante esta classificação, tem-se a análise do padrão de especialização do comércio internacional do setor agrícola brasileiro, descrita na próxima seção.

\section{RESULTADO E DISCUSSÃO}

\subsection{TAXA DE COBERTURA DAS IMPORTAÇÕES - TC}

Sendo a taxa de cobertura das importações maior que a unidade, indica-se que em determinado setor as exportações brasileiras agrícolas teriam uma dimensão maior se comparadas às importações do mesmo setor.

Os quatro produtos mais relevantes na pauta exportadora agrícola brasileira, os quais apresentam maiores taxas de cobertura, ou maior vantagem comparativa em termos de cobertura das exportações, ordenados do maior ao menor, foram os setores de suco de laranja, açúcar e frango, com médias respectivamente de $131.376,85 ; 37.900,85 ; 2.733,22 ;$ no período de análise, conforme a Tabela 3.

Tabela 3. Taxa de cobertura das importações agrícolas brasileiras (em razão)

(Continua)

\begin{tabular}{cccccccccc}
\hline Produtos & $\begin{array}{c}\text { Soja e } \\
\text { derivados }\end{array}$ & $\begin{array}{c}\text { Suco de } \\
\text { laranja }\end{array}$ & Fumo & Frango & $\begin{array}{c}\text { Carne } \\
\text { bovina }\end{array}$ & $\begin{array}{c}\text { Carne } \\
\text { suína }\end{array}$ & Açúcar & Café & Madeira \\
\hline 1999 & 21,8 & $8.112,87$ & 90,75 & $2.542,76$ & 9,78 & 27,61 & $57.857,72$ & $1.939,35$ & 22,23 \\
2000 & 22,6 & $5.487,14$ & 56,26 & $1.811,27$ & 7,17 & 81,97 & $36.062,86$ & $1.146,89$ & 19,31 \\
2001 & 25,24 & $24.764,02$ & 40,71 & $7.177,70$ & 16,16 & 245,95 & $81.267,95$ & 662,07 & 22,79 \\
2002 & 16,16 & $161.785,72$ & 34,29 & $1.349,11$ & 11,98 & 399,06 & $56.249,53$ & 493,94 & 26,99 \\
2003 & 17,55 & $1.357 .850,96$ & 32,44 & $2.668,11$ & 15,78 & 415,19 & $54.908,83$ & 784,68 & 21,53 \\
2004 & 51,8 & $146.134,23$ & 53,89 & $5.944,82$ & 21,28 & 521,67 & $14.577,87$ & 879,33 & 23,34 \\
2005 & 56,97 & $27.106,49$ & 58,89 & $3.198,62$ & 21,96 & 641,59 & $56.920,29$ & $1.192,62$ & 21,35 \\
2006 & 126,95 & $10.265,22$ & 44,07 & $3.690,47$ & 38,37 & 351,21 & $49.368,25$ & $1.186,24$ & 17,21 \\
2007 & 88,73 & $22.938,69$ & 45,13 & $2.715,20$ & 33,48 & 354,94 & $27.655,74$ & $1.072,49$ & 16,79 \\
& & & & & & & & & \\
\hline
\end{tabular}


(Conclusão)

\begin{tabular}{cccccccccc}
\hline Produtos & $\begin{array}{c}\text { Soja e } \\
\text { derivados }\end{array}$ & $\begin{array}{c}\text { Suco de } \\
\text { laranja }\end{array}$ & Fumo & Frango & $\begin{array}{c}\text { Carne } \\
\text { bovina }\end{array}$ & $\begin{array}{c}\text { Carne } \\
\text { suína }\end{array}$ & Açúcar & Café & Madeira \\
\hline 2008 & 140,01 & $179.867,32$ & 52,49 & $3.847,32$ & 34,87 & 373,77 & $22.422,16$ & 496,73 & 12,76 \\
2009 & 183,58 & $154.374,86$ & 38,69 & $3.354,26$ & 25,99 & 255,17 & $42.784,76$ & 218,04 & 11,42 \\
2010 & 203,01 & 383,87 & 35 & $1.906,09$ & 24,25 & 189,11 & $32.825,92$ & 214,06 & 11,63 \\
2011 & 635,16 & 333,36 & 72,24 & 957 & 18,45 & 129,27 & $36.930,47$ & 170,53 & 8,57 \\
2012 & 144,35 & 948,51 & 81,27 & $1.141,24$ & 16,86 & 115,03 & $17.848,09$ & 142,29 & 9,26 \\
2013 & 205,34 & $1.056,77$ & 68,24 & 761,67 & 22,43 & 95,05 & $10.197,16$ & 130,21 & 12,1 \\
2014 & 119,52 & 619,57 & 58,21 & 665,92 & 17,9 & 95,79 & $8.535,92$ & 113,03 & 13,47 \\
\hline
\end{tabular}

Fonte: Elaboração própria a partir dos dados do Sistema Alice Web.

O setor que apresentou maior taxa de cobertura das importações foi o do suco de laranja. O mercado mundial de suco de laranja é liderado pelo Brasil e pelos Estados Unidos, e o Brasil representa mais de 80,0\% das exportações mundiais do suco de laranja concentrado e congelado (COSTA; MAIA; SAMPAIO, 2012). Neste contexto, São Paulo é o principal Estado brasileiro exportador de suco de laranja, representando 94,9\% das exportações brasileiras do produto de 1999 a 2014 (ALICE WEB, 2015).

Para o suco de laranja, a competividade deve-se à oferta abundante e alta qualidade para a produção de sucos, ao clima favorável e safra durante o ano todo, ao baixo custo de produção, à proximidade do setor produtivo e do canal de escoamento, bem como pela presença de indústrias de grande escala, com navios próprios para distribuição de suco e armazéns de portos particulares (GOVERNO DO ESTADO DE SÃO PAULO, 2016).

De acordo com a Tabela 3, o setor de açúcar obteve a segunda maior taxa de cobertura das importações. O mercado mundial do setor sucroalcooleiro é liderado por Brasil, Tailândia, Austrália e Índia (SECRETARIA DE ESTADO DA AGRICULTURA E DO ABASTECIMENTO DO PARANÁ - SEAB, 2013).

Os Estados de São Paulo, Paraná e Minas Gerais são os principais exportadores de açúcar do país. Apenas as exportações paulistas do produto representam 65,1\% das exportações brasileiras do bem de 1999 a 2014 (UNIÃO DA INDÚSTRIA DE 
CANA-DE-AÇÚCAR - UNICA, 2016; ALICE WEB, 2015). A competitividade do setor sucroalcooleiro está atrelada à qualidade do solo e ao clima favorável ao cultivo, à mão de obra qualificada nas diversas etapas da cadeia produtiva, à alta tecnologia e presença de institutos de pesquisa aplicada (GOVERNO DO ESTADO DE SÃO PAULO, 2016).

Além disso, o setor de carne de frango apresentou a terceira maior taxa de cobertura das importações. O mercado mundial de carne de frango é liderado por Brasil, Estados Unidos e União Europeia (BRAZILIAN CHICKEN, 2011). Desta forma, os Estados de Santa Catarina, Paraná, Rio Grande do Sul e São Paulo são os principais exportadores de carne de frango do país (BALDI et al., 2013). Apenas as exportações catarinenses do produto representam 29,4\% das exportações brasileiras do bem de 1999 a 2014 (ALICE WEB, 2015). A competitividade do setor de carne de frango deve-se à disponibilidade de farelo de soja e milho para ração. Além disso, a competitividade do setor resulta do processo de reestruturação industrial, de mudanças tecnológicas e de melhorias nas técnicas de manejo, nutrição e sanidade das aves (SILVA et al., 2011).

Conforme a Tabela 3, é importante destacar que todos os demais setores indicaram que as exportações cobrem as importações, sendo, portanto, competitivos no comércio de produtos agrícolas brasileiros.

\section{2 ÍNDICE DE COMÉRCIO INTRAINDÚSTRIA - CII}

Na Tabela 4, apresentam-se os resultados do CII, o qual representa o padrão comercial dentro de um mesmo setor, e, quando for maior que 0,5 aponta comércio intraindustrial, caso contrário, interindustrial. Dos nove setores analisados, todos indicaram haver comércio interindústria ao longo de todo o período analisado, de acordo com a Tabela 4. 


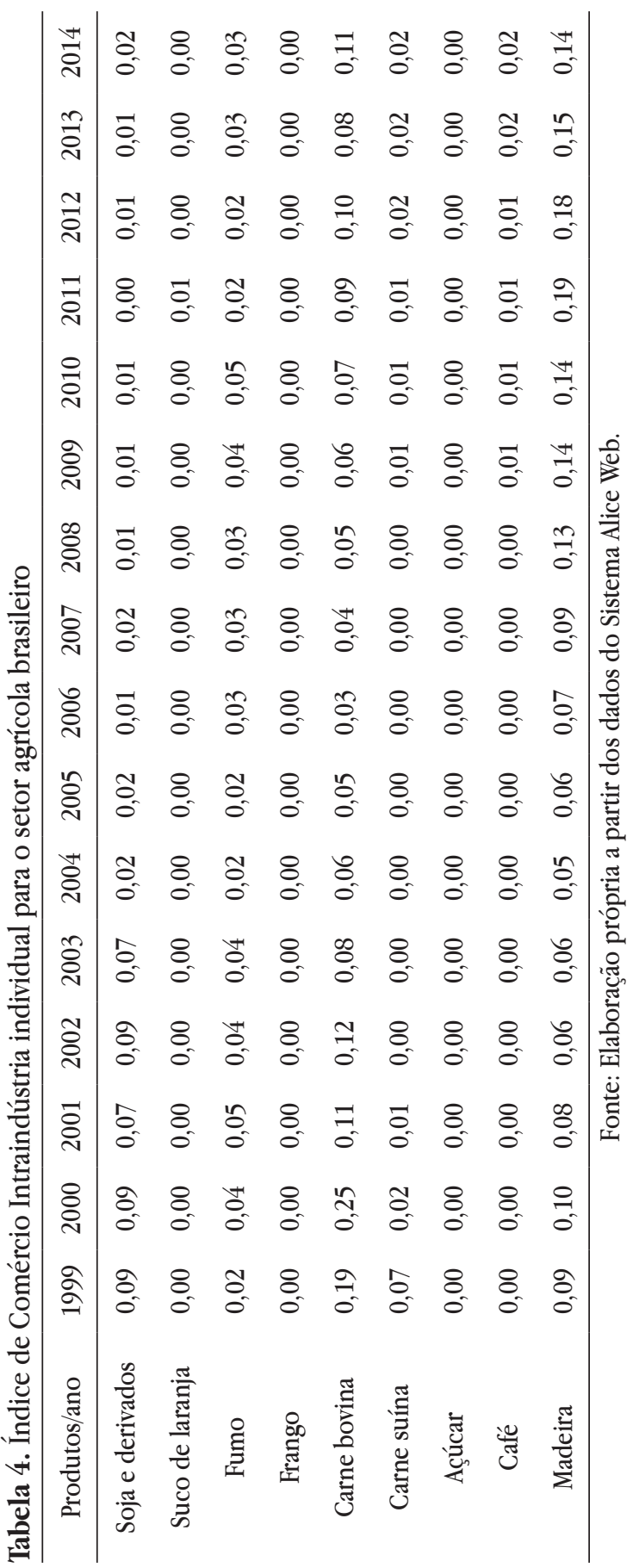


Neste sentido, pode-se sugerir que o modelo comercial agrícola brasileiro se baseia na dotação intensiva de recursos naturais, como condições ideais de clima, hidrografia e geologia para o cultivo (SILVA et al., 2015).

Além disso, o melhoramento genético, o investimento em tecnologias, a ampliação da produtividade, a rotação de culturas e o plantio direto podem ser considerados fatores competitivos para o padrão comercial interindustrial (FRIES et al., 2013).

É importante ressaltar que a análise do padrão de especialização do comércio agrícola brasileiro pode ser verificada de forma agregada, de acordo com a Tabela 5 .

Tabela 5. Índice de comércio intraindústria - CII agregado para o setor agrícola brasileiro

\begin{tabular}{cccc}
\hline Ano & CII & Ano & CII \\
\hline 1999 & 0,05 & 2007 & 0,02 \\
2000 & 0,06 & 2008 & 0,02 \\
2001 & 0,05 & 2009 & 0,02 \\
2002 & 0,05 & 2010 & 0,02 \\
2003 & 0,04 & 2011 & 0,02 \\
2004 & 0,02 & 2012 & 0,02 \\
2005 & 0,02 & 2013 & 0,02 \\
2006 & 0,02 & 2014 & 0,03 \\
\hline
\end{tabular}

Fonte: Elaboração própria a partir dos dados do Sistema Alice Web.

Para análise dos setores agregados no CII, os resultados indicaram comércio interindustrial para o mercado agrícola, variando em torno de 3,0\% entre 1999 e 2014. Desta forma, em média, o Brasil apresenta especialização nos setores agrícolas com vantagens comparativas.

\section{3 ÍNDICE DE CONCENTRAÇÃO SETORIAL DAS EXPORTAÇÕES - ICS}

Na Tabela 6, apresentam-se os resultados do ICS das exportações agrícolas brasileiras. Quanto mais próximo a 1, mais concentradas serão as exportações 
em poucos setores. Porém, quanto mais próximo de 0 , mais diversificada será a composição da pauta exportadora.

Tabela 6. Índice de Concentração Setorial das exportações para o setor agrícola brasileiro

\begin{tabular}{llll}
\hline Ano & CII & Ano & CII \\
\hline 1999 & 0,11 & 2007 & 0,10 \\
2000 & 0,10 & 2008 & 0,11 \\
2001 & 0,11 & 2009 & 0,14 \\
2002 & 0,12 & 2010 & 0,12 \\
2003 & 0,13 & 2011 & 0,12 \\
2004 & 0,12 & 2012 & 0,13 \\
2005 & 0,10 & 2013 & 0,15 \\
2006 & 0,10 & 2014 & 0,16 \\
\hline
\end{tabular}

Fonte: Elaboração própria a partir dos dados do Sistema Alice Web

Desta forma, de acordo com a Tabela 6 , pode-se sugerir que o Brasil apresenta uma pauta de exportações agrícolas diversificada, com a média do indicador de 0,12 , no período analisado, oscilando entre 0,10 e 0,16.

Esse resultado é reflexo do padrão interindustrial comercial, uma vez que todos os setores agrícolas analisados apresentam comércio baseado nas vantagens comparativas. Além disso, conforme o Sistema Alice Web (2015), ao longo do período, os setores que mais aumentaram as exportações foram carne suína, carne bovina, soja e derivados e frango. Porém, os setores que apresentaram menor crescimento foram madeira e suco de laranja.

\section{CONSIDERAÇÕES FINAIS}

Este estudo permitiu elucidar o padrão do comércio exterior dos diversos setores agrícolas brasileiros. As observações conjuntas das evidências empíricas apresentadas neste artigo permitiram destacar as peculiaridades setoriais da 
competitividade do país no comércio exterior agrícola, mostrando que todos os setores agrícolas analisados são competitivos no mercado internacional, com ênfase para o suco de laranja, açúcar e frango.

A partir da estrutura das exportações agrícolas brasileiras, foi possível analisar que estas cresceram em ritmos elevados. O padrão das importações feitas pelo país não se alterou, sendo de pequena participação.

Desta forma, pode-se ressaltar que o comércio agrícola brasileiro obedece a um comportamento predominantemente interindustrial, ou seja, baseado nas vantagens comparativas. Ainda neste contexto, é possível afirmar que o Brasil apresenta uma pauta exportadora agrícola diversificada.

A partir deste contexto, ressalta-se que a abertura comercial, os ganhos de produtividade por meio da evolução tecnológica, o clima propício e a extensão territorial brasileira são fatores que afetaram positivamente o desempenho do setor agrícola brasileiro no período analisado. Podem-se destacar também outros fatores que influenciaram não só o agronegócio brasileiro, mas a economia brasileira como um todo, exemplo disso é o efeito-China, o qual ocasionou na suba dos preços internacionais das commodities.

Porém, o custo-Brasil, representado pelos custos de infraestrutura, de transporte e de portos, da elevada taxa de juros, da carga tributária elevada e dos custos trabalhistas e previdenciários e a crise financeira, primeiramente nos Estados Unidos e, posteriormente, na União Europeia, podem ter impactado de forma negativa na performance agrícola do país.

Por isso, à luz das teorias de comércio internacional, sugere-se, como política de crescimento e desenvolvimento do setor agrícola brasileiro, aproveitar a entrada de divisas internacionais em setores que já possuem vantagem comparativa para aumentar a sua produtividade intrassetorial e extrassetorial e estimular o crescimento das indústrias a jusante e a montante, pois tal expansão do setor poderá trazer benefícios para os demais setores na região por meio do aumento na renda local.

Como limitações do trabalho, destaca-se que os índices utilizados são estáticos, pois não compreendem alterações em fatores econômicos como barreiras comerciais, tratados de livre comércio, variações no consumo interno, entre outros. 
Neste sentido, sugere-se a realização de estudos futuros com a utilização de Modelos de Equilíbrio Geral Dinâmicos, com o intuito de identificar os impactos de políticas econômicas na economia agrícola brasileira bem como estudar os setores mais específicos em busca de descobrir quais são os fatores internos e externos que mais influenciam na produtividade e desempenho de cada um.

\section{REFERÊNCIAS}

ALBUQUERQUE, C. R.; FERNANDES, C. L. L. Impactos da liberalização comercial no perfil do comércio exterior brasileiro. In: ENCONTRO NACIONAL DE ECONOMIA - ANPEC, 27., 1999, Belém. Anais... Belém, 1999.

ANÁLISE DAS INFORMAÇÕES DE COMÉRCIO EXTERIOR (ALICE WEB). Consultas. Disponível em: < http://aliceweb.mdic.gov.br/> Acesso em: 09 jan. 2015.

APPLEYARD, D.; FIELD JR., A, J.; COBB, S. L. Economia Internacional. 6. ed. Porto Alegre: McGraw Hill, 2010.

BALDI, M.; KRÜGER, L.; OLIVEIRA, G.; MORES, G. V. Análise da transmissão de preços da carne de frango entre os principais estados produtores brasileiros e os Estados Unidos. In: ENCONTRO DE ECONOMIA DA REGIÃO SUL - ANPEC/SUL, 16., 2013, Curitiba. Anais... Curitiba, 2013.

BERGSTRAND, J. H.; EGGER, P. Trade costs and intra-industry trade. Review of World Economics, v. 3, n. 142, p. 433-458, 2006.

BRANDÃO, A. S. P.; REZENDE, G. C.; MARQUES, R. W. C. Crescimento agrícola no Brasil no período 1999-2004: explosão da soja e da pecuária bovina e seu impacto sobre o meio ambiente. Rio de Janeiro, 2005. (Texto para Discussão IPEA, n. 1103).

BRAZILIAN CHICKEN. A Indústria Avícola. Disponível em: < http://www.brazilianchicken.com.br/home/ofrangonomundo?lang=pt>. Acesso em: 20 dez. 2011.

BRESSER-PEREIRA, L. C.; VIANA, A. G.; CUNHA, P. H. F. Reflexões sobre o Novo Desenvolvimentismo e o Desenvolvimentismo Clássico. Revista de Economia Política, v. 36, n. 2, p. 143, 2016. 
CARMO, A. S. S. do. O comércio intra-industrial e os seus determinantes: uma investigação empírica para o Brasil. 2010. 116 f. Dissertação (Mestrado em Desenvolvimento Econômico) - Programa de Pós-graduação em Desenvolvimento Econômico, Universidade Federal do Paraná, Curitiba. 2010.

CARVALHO, M. A. Exportações agrícolas e desindustrialização: uma contribuição ao debate. In: CONGRESSO BRASILEIRO DE ECONOMIA E SOCIOLOGIA RURAL, 2006, 44.,, Fortaleza. Anais... Fortaleza, CD-ROM, 2006.

CARVALHO, F. L. de; BIALOSKORSKI NETO, S. Indicadores de avaliação de desempenho econômico em cooperativas agropecuárias: um estudo em cooperativas paulistas. Organizações Rurais \& Agroindústrias, Lavras, v.10, n. 3, 2008.

CASAGRANDE, D. L.; ILHA, A. D.; FÜHR, J. Intercâmbio comercial entre Rio Grande do Sul e China de 2000 a 2010. Perspectiva Econômica, v. 9, n. 1, p.17-30, 2013.

CONCEIÇÃO, J. C. P. R.; CONCEIÇÃO, P. H. Z. Agricultura: evolução e importância para a balança comercial brasileira. Brasília, 2014. (Texto para Discussão IPEA, n. 1944).

CORONEL, D. A.; MACHADO, J. A. D.; CARVALHO, F. M. A. D. Análise da competitividade das exportações do complexo soja brasileiro de 1995 a 2006: uma abordagem de market-share. Revista de Economia Contemporânea, v. 13, p. 281-308, 2009.

COSTA, C. K. F.; MAIA, S. F.; SAMPAIO, L. M. B. Exportações brasileiras de suco de laranja e subsídios americanos: uma análise empírica de estratégias comerciais (19912006). Revista de Economia e Sociologia Rural, Brasília, v. 50, n.1, jan./mar. 2012.

DION, D-P. Trade, growth and geography: a synthetic approach. Discussion Paper, Department of Economics, University of Mannheim, n. 22, 2004.

FEISTEL, P. R.; HIDALGO, A. B. O Intercâmbio comercial nordeste-China: desempenho e perspectivas. Revista Econômica do Nordeste, v. 42, n. 4, p. 761-777, 2011.

FONTENELE, A. M. de C.; MELO, M. C. P.; ROSA, A. L. T. A Indústria Nordestina Sob a Ótica da Competitividade Sistêmica. Fortaleza: EUFC/SUDENE/ACEP, 2000. 
FRIES, C. D.; CORONEL, D. A.; VIEIRA, K. M.; BENDER FILHO, R. Avaliação do crescimento das exportações do agronegócio gaúcho: uma aplicação do método constant -market-share. Revista Eletrônica em Gestão, Educação e Tecnologia Ambiental - REGET/UFSM, v. 17, n. 17, dez. 2013.

GASQUES, J.G.; REZENDE, G.C.; VERDE, C.M.V.; SALERMO, M.S.; CONCEIÇÃO, J.C.P.R.; CARVALHO, J.C.S. Desempenho e crescimento do agronegócio no Brasil. Texto para Discussão IPEA, Brasília, n. 1009, 2004.

GRUBEL, H.; LLOYD, P. Intra-Industry Trade: the theory and the measurement of international trade in differentiated products. London: Macmillan, 1975.

GOVERNO DO ESTADO DE SÃO PAULO. Setores de negócios, agronegócios. Disponível em: <http://www.investe.sp.gov.br/setores-de-negocios/agronegocios/ laranja/> . Acesso em: 9 jan. 2016.

HELPMAN, E.; KRUGMAN, P. Market structure and foreign trade: increasing returns imperfect competition and the international economy. Cambridge: MIT Press, 1985.

INSTITUTO BRASILEIRO DE ECONOMIA. Estudos agrícolas. Disponível em: $<$ http://portalibre.fgv.br/main.jsp?lumChannelId=8A7C8233253AEA0A01253AF9C3144F4B >. Acesso em: 15 fev. 2017.

JAMBOR, A.; LEITÃO, N. C. Industry-specific determinants of vertical intra-industry trade: the case of EU new member states' agri-food sector. Post-Communist Economies, v. 1, n. 28, p. 34-48, 2016.

LIMA, C. E.; MORETTO, A. C.; RODRIGUES, R. L. Mercado de Carne Bovina no Brasil: Oferta e Demanda no período 2000 a 2009. In: XLIX CONGRESSO BRASILEIRO DE ECONOMIA E SOCIOLOGIA RURAL, 2011, Belo Horizonte. Anais... Belo Horizonte, CD-ROM.

MINISTÉRIO DA AGRICULTURA, PECUÁRIA E ABASTECIMENTO (MAPA). Secretaria de Política Agrícola. Disponível em: < http://www.agricultura.gov.br/> Acesso em: 29 dez. 2015. 
MINISTÉRIO DO DESENVOLIMENTO DA INDÚSTRIA E COMERCIO EXTERIOR (MDIC). Secretaria de Comércio Exterior (SECEX). Disponível em: < http://www. mdic.gov.br/sitio/> . Acesso em: 31 jan. 2015.

ORGANIZAÇÃO DAS NAÇÕES UNIDAS PARA AGRICULTURA E ALIMENTAÇÃO (FAO). Agriculture And Consumer Protection. Disponível em: < http://www.fao.org/ag/ portal/ag-home/en/ > . Acesso em: 18 dez. 2015.

ORGANIZAÇÃO PARA A COOPERAÇÃO E DESENVOLVIMENTO DA EUROPA (OCDE). Brazil country Surveys. Disponível em: < http://www.oecd.org/brazil/publicationsdocuments/reports/> . Acesso em: 18 dez. 2015.

PORTER, M. A vantagem competitiva das nações. 15. ed. Rio de Janeiro: Elsevier, 1993.

POSSAS, M S. Concorrência e Competitividade: Notas Sobre Estratégia e Dinâmica Seletiva na Economia Capitalista. 1993. 245 f. Tese (Doutorado em Economia) - Instituto de Economia, Universidade Estadual de Campinas, Campinas. 1993.

SECRETARIA DE ESTADO DA AGRICULTURA E DO ABASTECIMENTO DO PARANÁ (SEAB). Cana de açúcar e Sucroalcooleiro: Prognóstico. Disponível em: < http:// www.agricultura.pr.gov.br/arquivos/File/deral/Prognosticos/cana_2012_13.pdf $>$. Acesso em: 20 dez. 2013.

SILVA, M. A. P.; ROSADO, P. L.; BRAGA, M. J.; CAMPOS, A. C. Oferta de exportação de carne de frango do Brasil, de 1992 a 2007. Revista de Economia e Sociologia Rural, v. 49, n.1, Brasília, jan./mar. 2011.

SILVA, M. L.; SILVA, R. A.; CONTE, B. C.; LERMEN, N. G.; CORONEL, D. A.; BENDER FILHO, R. Análise da competitividade das exportações gaúchas para a China (19992013). Ciências Sociais em Perspectiva, v. 14, n. 27, p. 20-39, 2015.

SOO, K. T. Intra-industry trade: A Krugman-Ricardo Model and Data. Economica, n. 83, p. 338-355, 2016. 
UNIÃO DA INDÚSTRIA DE CANA-DE-AÇÚCAR-UNICA. Exportação anual de açúcar pelo Brasil por estado de origem. Disponível em: < http://www.unicadata.com.br/ listagem.php?idMn=43>. Acesso em: 20 jan. 2016.

UNITED STATES DEPARTMENT AGRICULTURE (USDA). Agency Reports. Disponível em: < http://www.usda.gov>. Acesso em: 05 mar. 2016.

VASCONCELOS, C. R. F. O comércio Brasil-Mercosul na década de 90: Uma análise pelas éticas da intensidade fatorial, comércio intraindustria e criação e desvio de comércio. 2000. 221 f. Tese (Doutorado em Economia) - Universidade Federal de Pernambuco, Recife. 2000.

VERÍSSIMO, A. Panorama da carne brasileira no mercado mundial e o marketing internacional. Biológico, v. 69, p. 35-37, 2007.

VIANNA, S. T. W.; BRUNO, M. A. P.; MODENESI, A. M. Macroeconomia para o Desenvolvimento: crescimento, estabilidade e emprego. 4. ed. Rio de Janeiro: IPEA, 2010.

WAQUIL, P. D.; ALVIM, A. M.; SILVA, L. X.; TRAPP, G. P. Vantagens comparativas reveladas e orientação regional das exportações agrícolas brasileiras para a União Européia. Revista de Economia e Agronegócio, Viçosa, v. 2, n. 2, p. 137-160, 2004.

Recebido em: $12 / 03 / 2016$ Aceito em: 31/03/2017 